\title{
Multi-scale study of normal aging predicts novel late-onset Alzheimer's disease risk variants
}

\author{
Sarah M Neuner ${ }^{1}$, Lynda Wilmott ${ }^{1}$, Matthew DeBoth², Thomas Shapaker ${ }^{1}$, Jesse Ingels ${ }^{3}$, Lu Lu ${ }^{3}$, Rob Williams ${ }^{3}$, \\ Gerd Kempermann ${ }^{4}$, Matthew Huentelman ${ }^{2}$, Catherine C Kaczorowski ${ }^{*}$ \\ From 14th Annual UT-KBRIN Bioinformatics Summit 2015 \\ Buchanan, TN, USA. 20-22 March 2015
}

\section{Background}

Alzheimer's disease (AD) is a neurodegenerative disorder characterized by severe memory impairment and accumulation of neuropathological amyloid plaques and tau tangles. By contrast, 'normal' age-associated cognitive decline is less severe and generally occurs in the absence of neuropathology. Many believe aging- and AD-related memory impairments result from separate etiologies, but this distinction is not entirely consistent with emerging evidence that both are linked to hippocampal dysfunction. As aging is the most significant risk factor for late-onset AD (LOAD), we hypothesize that memory deficits in both 'normal' aging and AD are driven in part by some common underlying mechanisms, which are exacerbated in AD by disease-specific insults such as neurodegeneration, neuroinflammation, and neuropathologies. In addition, heritability estimates suggest a strong genetic component $(50-80 \%)$ in both conditions $[1,2]$. Thus, elucidating genetic correlates of memory decline in 'normal' aging may identify risk factors that influence susceptibility to LOAD.

\section{Materials and methods}

Given that genetically diverse mouse models have emerged as a powerful way to study complex human traits, we conducted a multi-scalar analysis of two independent mouse models of aging to test this hypothesis [3]. We combined memory tests with proteomic, transcriptomic, and genomic data to generate a list of the top 30 candidates that correlate with memory impairments. To evaluate the translational potential of these candidates, we performed secondary analysis using published

\footnotetext{
* Correspondence: ckaczoro@uthsc.edu

'Department of Anatomy and Neurobiology, University of Tennessee Health Science Center, Memphis, TN 38163, USA

Full list of author information is available at the end of the article
}

hippocampal transcript data from LOAD patients relative to age-matched non-demented controls [4].

\section{Results}

Eighteen genes including TRPC3, GABRA3, GABRA5, GABRB1, GABRB2, WDFY3, and GRM1 were significantly differentially expressed relative to disease status, suggesting they may play a role in the human disease process. In addition, we wanted to identify whether any of our candidate genes contained single nucleotide polymorphisms (SNPs) that could be used to predict an individual's susceptibility to LOAD. To test the ability of our multi-scalar approach to detect known LOAD risk genes, we searched our full dataset for published risk genes. We identified APOE, SORL1, EPHA1, BIN1, and TREM2 as significantly differentially expressed relative to memory function in our aging models, validating our approach. We then tested our novel candidates against the freely available ADGC "TGEN2" dataset that is a clinical characterized and neuropathologically verified cohort $[5,6]$. Our analysis yielded four nominally significant novel putative risk variants (GABRB1, GABRB2, GRM1, and WDFY3) using data generated by our study of aging models.

\section{Conclusions}

Future work will investigate functional significance of these SNPs and validate mechanistic relevance to cognitive decline during aging and AD. This work demonstrates the utility of studying 'normal' aging models to both better understand molecular mechanisms mediating memory function in diverse populations and to identify those candidates with the best potential to translate into effective treatments and predictive biomarkers for cognitive decline in elderly humans. 


\section{Acknowledgments}

Supported by NIH/NIA grant K99/R00 AG039511 (PI: Kaczorowski), NIH/NIA grant F31 AG050357 (PI: Neuner), and the American Federation for Aging grant RAG14141 (Pl:Kaczorowski).

\section{Authors' details}

'Department of Anatomy and Neurobiology, University of Tennessee Health Science Center, Memphis, TN 38163, USA. ${ }^{2}$ Translational Genomics Research Institute (TGEN), Phoenix, AZ 85004, USA. ${ }^{3}$ Department of Genetics,

Genomics, and Informatics, University of Tennessee Health Science Center, Memphis, TN 38163, USA. ${ }^{4}$ Center for Regenerative Therapies,

TechnischeUnivsersitat Dresden, Dresden, 01307, Germany.

\section{Published: 23 October 2015}

\section{References}

1. Wilson RS, Barral S, Lee JH, Leurgans SE, Foroud TM, Sweet RA, et al: Heritability of different forms of memory in the Late Onset Alzheimer's Disease Family Study. J Alzheimers Dis 2011, 23(2):249-255.

2. Deary IJ, Yang J, Davies G, Harris SE, Tenesa A, Liewald D, et al: Genetic contributions to stability and change in intelligence from childhood to old age. Nature 2010, 482(7384):212-215.

3. Neuner SM, Wilmott LA, Hope KA, Hoffmann B, Chong JA, Abramowitz J, et al: TRPC3 channels critically regulate hippocampal excitability and contextual fear memory. Behav Brain Res 2015, 281:69-77.

4. Liang WS, Reiman EM, Valla J, Dunckley T, Beach TG, Grover A, et al: Alzheimer's disease is associated with reduced expression of energy metabolism genes in posterior cingulate neurons. Proc Natl Acad Sci U S A 2008, 105(11):4441-4466.

5. Corneveaux JJ, Myers AJ, Allen AN, Pruzin JJ, Ramirez M, Engel A, et al: Association of CR1, CLU and PICALM with Alzheimer's disease in a cohort of clinically characterized and neuropathologically verified individuals. Hum Mol Genet 2010, 19(16):3295-3301.

6. Reiman EM, Webster JA, Myers AJ, Hardy J, Dunckley T, Zismann VL, et al: GAB2 alleles modify Alzheimer's risk in APOE epsilon4 carriers. Neuron 2007, 54(5):713-720.

doi:10.1186/1471-2105-16-S15-P11

Cite this article as: Neuner et al:: Multi-scale study of normal aging predicts novel late-onset Alzheimer's disease risk variants. $B M C$ Bioinformatics 2015 16(Suppl 15):P11.

\section{Submit your next manuscript to BioMed Central and take full advantage of:}

- Convenient online submission

- Thorough peer review

- No space constraints or color figure charges

- Immediate publication on acceptance

- Inclusion in PubMed, CAS, Scopus and Google Scholar

- Research which is freely available for redistribution

Submit your manuscript at www.biomedcentral.com/submit
Biomed Central 